\title{
Pathology of Takhti and Imam Reza Football Stadiums in Mashhad with Emphasis on Passive Defense
}

\author{
Shahram Abdi ${ }^{1} \oplus$, Hasan Ghamati ${ }^{2} \oplus$, Ahmad Mahmoudi ${ }^{3} \oplus$, Mohammad Ghanbari $^{4,5}(\mathbb{\infty}$
}

Date of submission: 21 Jul. $2021 \quad$ Date of acceptance: 23 Oct. 2021

\begin{abstract}
INTRODUCTION: Nowadays, paying attention to the significance of football stadiums as important urban facilities and applying the principles of passive defense in them are among critical areas in the field of urban management. Given that, the primary goal of the present research is to investigate the pathology of football stadiums with an emphasis on passive defense.

METHODS: The present study is applied in terms of purpose and descriptive-analytical in terms of the research approach. Data collection was accomplished through documentary and field studies. In the documentary domain, information and data were gathered from the website of sports complexes, publications, and brochures. Regarding the field domain, spatial data related to the city of Mashhad were collected from the database and field studies in the form of observations and interviews with stadium officials. The target stadiums in the present study are Takhti and Imam Reza stadiums, which were studied based on two main criteria of design and location selection based on the principles of passive defense. After specifying the indicators, Arc GIS software was used to perform data analysis and spatial analysis operations.

FINDINGS: The research findings indicate that the most significant weaknesses of Takhti Stadium are the lack of access to first and secondary arterial roads, the presence of intersections and heavy traffic near the stadium, inadequate open space and parking lots, and lack of automatic fire suppression systems. The drawbacks of Imam Reza Stadium include the absence of shelter, no access to the subway stations, no direct access to primary arterial roads, and the absence of entrance and exit passageways in the stadium.
\end{abstract}

Original Article

CONCLUSION: The results indicate the fact that paying attention to the indicators and criteria of passive defense can extensively conserve and maintain sports facilities at times of crisis.

Keywords: Crisis Management; Passive Defense; Sports Stadium.

How to cite this article: Abdi Sh, Ghamati H, Mahmoudi A, Ghanbari M. Pathology of Takhti and Imam Reza Football Stadiums in Mashhad with Emphasis on Passive Defense. Sci J Rescue Relief 2021; 13(4): 263-71.

\section{Introduction}

$\mathrm{S}$

ince the beginning of time, man has always encountered all sorts of dangers, injuries, disasters, and invasions. Consequently, numerous human losses and financial damages have been inflicted on man. Therefore, various individuals and societies have been looking for ways to diminish the damage caused by emergencies and wars. These accidents are generally divided into two categories of natural and man-made disasters. The most fundamental factor in curtailing natural disasters is calculating the return period of these events and employing passive defense to design the defense structure $(1,2)$. With the increase in the number of wars, particularly in the past century, and the rise in injuries, casualties, financial and psychological losses for citizens, authorities, and government officials, along with political and diplomatic

1- PhD in Sport Management, Faculty of Sport Sciences, Ferdowsi University of Mashhad, Mashhad, Iran

2- PhD in Sport Management, Faculty of Humanities, Tarbiat Modares University, Tehran, Iran

3- Assistant Professor, Department of Sport Management, Faculty of Physical Education and Sport Sciences, University of Tehran, Tehran, Iran

4- $\mathrm{PhD}$ in Geography and Urban Planning, Ferdowsi University of Mashhad, Iran

5- Head of Process Improvement and Transformation Department of Mashhad Municipality, Mashhad, Iran

Correspondence to: Ahmad Mahmoudi, Email: ah.mahmoudi@ut.ac.ir 
efforts to diminish and prevent the formation of these wars, as well as military efforts to strengthen the defense of countries, countless other efforts are made in various domains and areas by leaders, officials and planners to curtail damages and casualties. Nowadays, these efforts and movements have been named passive defense and greatly pondered from a scientific perspective by officials and administrators (3). Any unarmed action that diminishes the vulnerability of a country's human resources, buildings, facilities, equipment, documents, and arterial roads against the enemy's hostile and destructive operations is dubbed passive defense. In a general sense, passive defense refers to a set of measures that do not require the use of weapons. By implementing passive defense, it is possible to prevent financial damage to vital and substantial military and civilian equipment and facilities and diminish human casualties or lessen the amount of these damages and losses to a minimum (4).

Passive defense in urban areas is extremely important economically, politically, socially, and culturally, etc. In this context, the primary purpose of urban defense is to protect citizens in defense and protect themselves against invasion and other incidents. As Frederick (2008) asserts, passive defense in urban society is to diminish vulnerability, enhance security, develop flexibility in various situations and demonstrate instantaneous reactions to save human lives, the lives of residents, and buildings. Additionally, passive defense is the effective protection of the lives of the citizens of a city against potential bombings (5). In addition to residential areas and the street network, service facilities also play an essential role in the proper functioning of the city and the satisfaction level of its citizens. Familiarity with the principles regulating the passive defense approach can be of great assistance to increase the efficiency and continuity of service facilities and facilities and service uses at times of crisis. These principles are a set of basic and infrastructural measures that, if applied, can accomplish the goals of passive defense (6). Passive defense against vulnerable urban patterns is one of the most crucial strategies for securing urban spaces proposed by planners. Safety and security against threats are some of the fundamental principles to achieve the eligible standards of urban comfort (7).

Among public buildings, there is no doubt that sports facilities, especially stadiums and sports fields, are incredibly valuable. They can be classified among the most susceptible and crucial centers (depending on the quality of service and radius of function). The destruction of such facilities may considerably increase disaster casualties and may even jeopardize the citizens' sense of psychological security. Establishing a safe environment for visitants to sports venues is one of the most critical tasks of the managing directors of such places. Moreover, the presence of a large number of people in one place will develop potential risks that are associated with significant factors such as structural deficiencies of the stadiums (8). At times of war, a stadium can act as a decent site to house, organize, and deploy individuals and citizens. Given the importance of stadiums and sports arenas at times of crisis, the necessity to pay attention to appropriate principles and regulations in locating and designing stadiums is exceptionally vital. The primacy of heeding to principles of passive defense in stadiums, arenas, and sports venues is undeniable. Organizations, institutions, and departments related to passive defense in sports complexes take this matter into account. As a result of the evolution of sports and consequently the surging interest in watching these events at sports venues and stadiums, the need to attend to passive defense is acknowledged more than ever.

Given the importance of football stadiums as significant facilities of a city and the fact that the practice of the principles of passive defense is one of the crucial and key areas in urban management and the need to comply with these principles in all areas and domains, the following question arises. What principles should football stadiums follow in terms of design and location with respect to passive defense to identify strengths weaknesses and thereafter to eradicate the weaknesses and boost the efficiency of strengths? Considering this issue, the primary research question is as follows: What is the pathology of Takhti and Imam Reza football stadiums in Mashhad with emphasis on passive defense?

\section{Methods}

The method of the present research study is applied in terms of purpose and descriptiveanalytical in terms of approach. This study investigates the pathology of Takhti and Imam Reza stadiums in Mashhad with an emphasis on 
passive defense. Some of the data and information were obtained through reviewing the theoretical foundations and research literature. However, the main data of the research, which included data regarding the stadiums of Mashhad, were attained from Mashhad's database of spatial data, websites of sports complexes, publications, and brochures published about stadiums. Furthermore, field studies were carried out in the form of observations and interviews with stadium officials. After identifying the target indicators, Arc GIS software was used to analyze the data. Information layers such as population block, subway transits, bus stations, fire departments, hospital spatial distribution, emergency bases, urban thoroughfares, green spaces, and facilities have been explored.

\section{Findings}

To analyze the research findings, the criteria were formulated by studying the theoretical foundations and research literature. These criteria were categorized into two major groups: 1 . how the stadiums are designed and constructed, and 2. how they are located and placed. The criteria are further investigated in more detail. Moreover, the target stadiums (Takhti and Imam Reza) will be assessed in the following.

\section{Design and construction of the stadiums Principles of camouflage and concealment}

These two concepts can be defined as follows. Camouflage diminishes the possibility of the forces, equipment, facilities, and activities being detected or recognized. Concealment includes hiding from the enemy's view (9). These two principles can be considered as the least costly solutions in preventing the damage of significant, susceptible, and vital facilities. By following these principles, facilities can be concealed from the enemy and the odds of them being identified and targeted can be minimized. Regarding camouflage and concealment in urban space, using green spaces and planting suitable trees inside the stadium environment and especially its surroundings can be considered as reasonable strategies, making it difficult to notice critical buildings and parts of the stadium. Other camouflage and concealment strategies include constructing buildings, particularly the exterior design, in a way that makes it difficult to notice, identify and target stadiums. Retaining a canopy and a roof over the stadium can prevent the athletes and spectators from being seen by the enemy. Takhti Stadium is located in the city center. Therefore, it is relatively concealed from a non-aerial perspective due to the vegetation and residential buildings. Nevertheless, from an aerial perspective, the stadium is certainly visible due to the lack of a roof. Imam Reza Stadium is more noticeable than the Takhti Stadium due to the lack of vegetation and residential buildings. Nevertheless, it is relatively concealed from an aerial view since it has a roof. Regarding the principle of camouflage, methods of homogenization which is using camouflage devices above and around the target so that the object blends with the natural background, can be utilized. Using appropriate nets and colors in the stadium's roof design, as well as the use of colors complementary to the background in the equipment section, can be among the solutions proposed in this domain.

\section{Principles of dispersion and decentralization}

This principle also has a considerable impact on reducing the vulnerability of critical centers in a country, especially stadiums and arenas. Fulfilling this principle, in addition to limiting the identification of the major and vital targets, reduces the enemy's ability to execute fire-andforget. Adherence to this principle also makes it possible for other departments to maintain their service if one department is targeted until the affected department returns to the service process. Considering the area of Takhti Stadium, it seems that this stadium has a high concentration in different sections. The presence of sports sections and office buildings in limited space has made this complex and stadium quite vulnerable. Regarding Imam Reza Stadium, we can mention the smaller concentration of sections and further dispersion of sports and office complexes. It should be noted that this stadium contains various sports halls beneath the spectator platforms, which has remarkably boosted the concentration in this area. It seems that in the design of sports stadiums, attending to this principle and building distinct parts of the stadium (including office, facilities, other sports halls, etc.) in a decentralized and scattered manner can diminish the enemy's fire-and-forget. Shelter

A shelter is a place that is more secure against 
the impacts of warfare (aerial-missile) or threats than common buildings or open areas (9). According to the investigations, Takhti Stadium does not have a shelter. However, the hall of late Sahraei (wrestling) and the hangars can be used as a shelter at times of crisis. Imam Reza Stadium does not have a shelter either. Nonetheless, as mentioned, other sports halls and hangars, as well as the lower floors of places (including the two lower floors in the parking lot) can be used for this purpose in times of crisis.

\section{Number of emergency evacuation exit routs}

The presence of several entrances and exits in convenient areas for major stadiums, especially at times of crisis, can remarkably decrease the turmoil provoked by swarms of individuals and cars surging. Likewise, the lack of such facilities influences the quality of service at the stadiums. Reviews show that Takhti Stadium has three entrances and exits including one in the northeast corner of Takhti Square, one in the west, and another in the south of the stadium. The number of entrances and exits of Takhti Stadium facilitates the movement of crowds and cars. However, considering that the nearby arterial roads are of the collector and distributor types, it seems that heavy traffic is often caused on such streets leading to hazardous accidents. There are two entrances for spectators to enter the stadium, and another entrance is designated for ambulances to enter the stadium. However, three entrances and exits are insufficient during emergencies. Furthermore, observations on Imam Reza Stadium show that this stadium has two entrances. One of these gates (southern door) is adjacent to a secondary arterial street, which is in a better condition in terms of traffic. Meanwhile, the other gate (northwestern door) is adjacent to the collector and distributor street, which will inevitably suffer from heavy traffic in case a sporting event is held. Possessing ten entrances and exits for spectators has made the evacuation time of the stadium much shorter than Takhti stadium.

\section{Location and placement}

Location is an essential element of the defense policy-making process. Typically, countries that vastly require defense policymaking adhere to defense issues, e.g., land-use planning and location. Taking such an approach into account, location refers to a set of measures that encourage establishing the capabilities of power in each country. According to such an approach, location refers to selecting the most appropriate, reasonable, and favorable point to base military and civilian units (10). One of the fundamental and major measures of passive defense is choosing the appropriate area and logical (correct and incorrect), scientific and military-strategic location (9). In the following, we will discuss how these two stadiums were located. Accessibility means the ease of reaching roads and transportation networks which can be formulated in various types and scales. Channels of communication from one position to the outside environment should be subject to criteria whose characteristics of threats lead to commute disruption, congestion, and elimination (11).

\section{Access to first and secondary arterial roads, local routes, and collector streets}

As presented in Figure 1, Takhti Stadium is

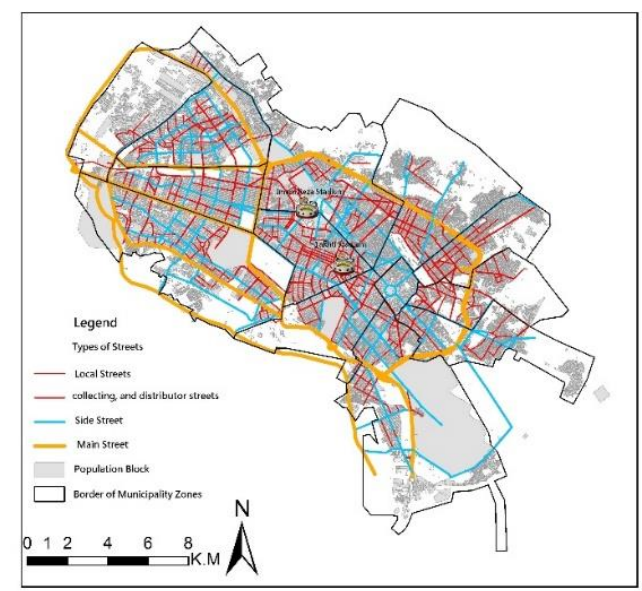

Figure 1. The stadiums' locations with respect to streets and urban routs 
located in Mashhad's downtown having no access to first and secondary arterial roads. More often than not, there is heavy traffic on local, collecting, and distributor streets. The traffic volume is often troublesome. Likewise, Imam Reza Stadium is located in the center of the city. Yet, unlike Takhti Stadium, it has access to the secondary arterial road, which withstands relatively smoother traffic. The stadium is linked to the Ghaem Highway from the northeast and the Azadi Highway from the west through secondary arterial roads. In general, Imam Reza Stadium is much more decently located than the accesses.

\section{Access to subway stations and bus stops}

As presented in Figure 2, due to the operation of Mashhad Subway Line 2, Takhti Stadium is in a good condition in terms of access to the subway stations. Imam Reza Stadium has no access to the subway network. The nearest subway station to this stadium is Khayyam Station which is $2.57 \mathrm{~km}$ far. Figure 3 demonstrates the location and distribution of bus stops for the two stadiums. Both stadiums are in decent conditions in terms of access to bus stops. However, it should be noted that considering the type of routes and transportation arterial roads, Imam Reza Stadium has better access to secondary arterial roads compared to Takhti Stadium, which suggests that bus and public transportation services are more facilitate and quicker on these routes.

\section{Access to fire stations}

One substantial indicator regarding safety considerations in locating stadiums is to check the quality of their access to fire stations, or whether the stadiums are equipped with fire hydrants to reduce the fire risk at times of crisis. As proposed in Figure 4, the dispersion of fire stations around the two stadiums is demonstrated. It seems that the higher the number of fire stations around the stadium, the higher the service rate of these stations to the stadium during emergencies. However, proximity to fire stations alone does not guarantee the safety of service to the stadium. Other factors such as accessibility to facilities and intersections near the hospital have a significant impact as well. The international standard recommends a radius of $5 \mathrm{~km}$ coverage for the fire stations. Moreover, the duration to reach the source of fire is 3 to 5 minutes (3). Figure 4 shows the presence of an adequate number of fire stations adjacent to Takhti Stadium. However, considering that Takhti Stadium is located in Mashhad's downtown, and the streets around the stadium are of the collector and distributor types, the accesses around this stadium withstand heavy traffic. Moreover, there are too many traffic lights and intersections around the stadium. This large number of traffic lights and intersections and the types of streets lead to disrupted access and make it complicated for fire stations to access the stadium at times of crisis.

\section{Access to hospitals, medical centers, and emergency headquarters}

Hospitals, as the front-liners of healthcare, are one of the most valuable sites for providing health
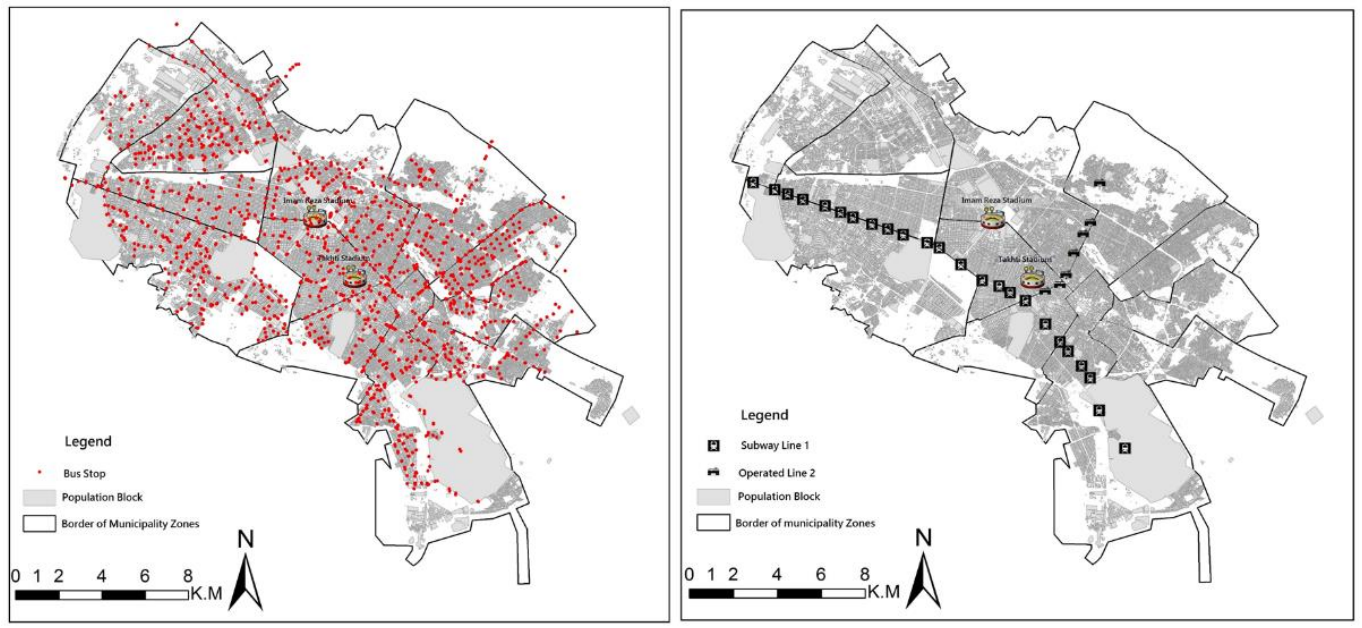

Figure 2. The stadiums' locations with respect to subway network

Figure 3. The stadiums' locations with respect to bus stops 


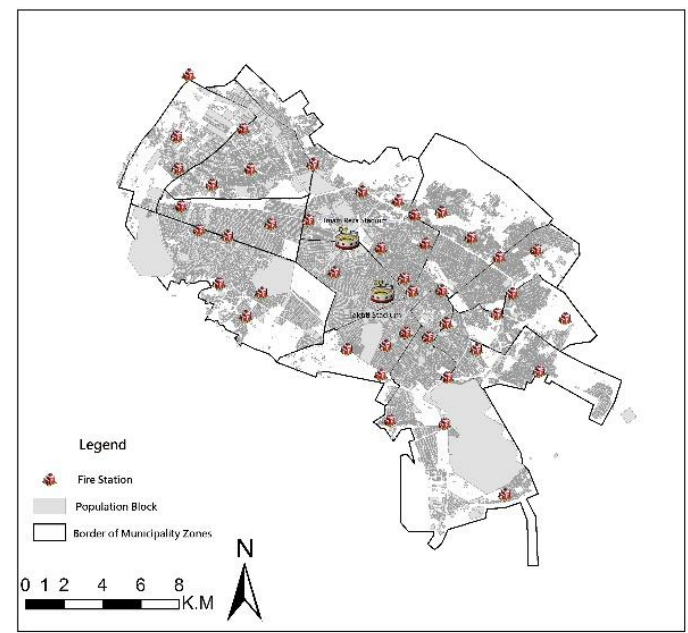

Figure 4. Spatial distribution of fire stations adjacent to Takhti and Imam Reza Stadiums
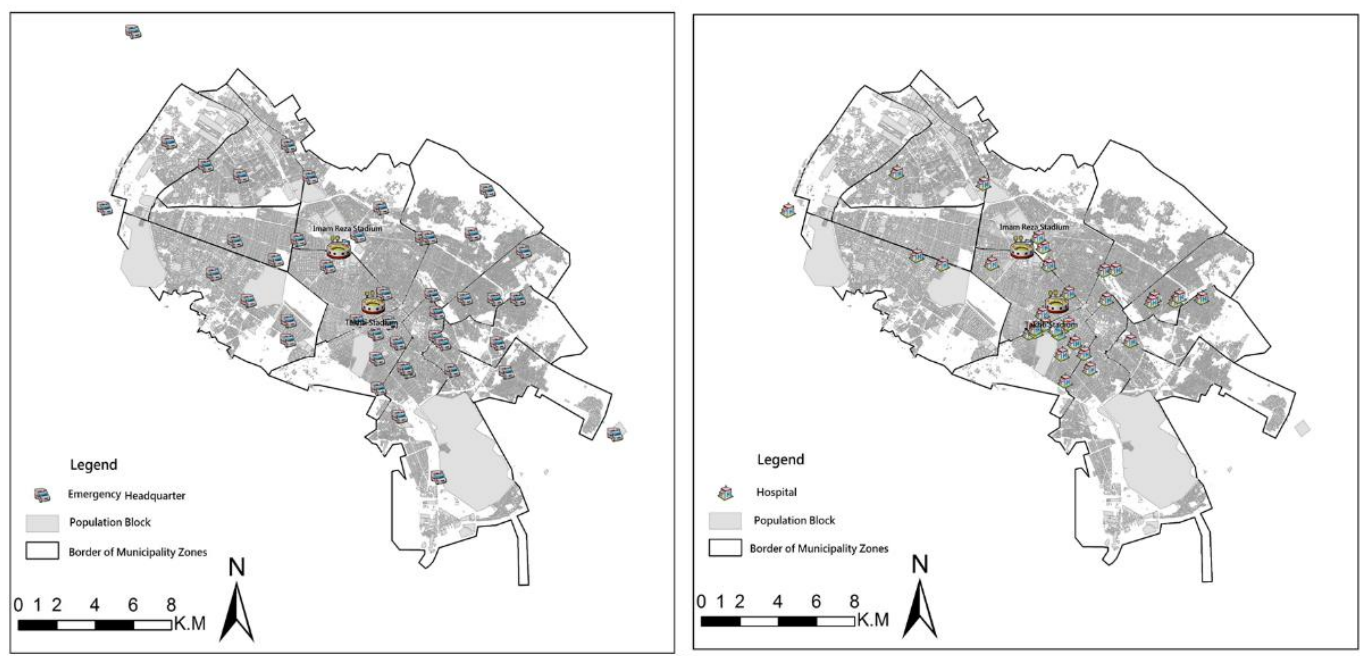

Figure 5. Spatial distribution of hospitals adjacent to the stadiums

Figure 6. Spatial distribution of emergency headquarters adjacent to the stadiums

services. Due to the nature of its activities and its role in the treatment and rehabilitation of the injured and the control of the health status of the community, the health sector has been susceptible and strategically significant (12). These types of facilities are directly related to rescue and treatment operations and provide a platform for this sequence (13). Regarding such facilities, it can be mentioned that some of them have value and primacy in terms of relief, including the Red Crescent Society and emergency services. Meanwhile, others are valuable for their healthcare and staff, such as hospitals and medical centers (14). Since potential crises might arise any second, decent access to such facilities is vital so that these centers can be put to good use without hesitation. According to Figure 5, Takhti Stadium has proper access to hospitals. Access to two major hospitals in Mashhad, i.e., Imam Reza and Ghaem hospitals, is a positive point about Takhti Stadium. It should be noted that in terms of access to the hospital, Imam Reza Stadium is in relatively good condition. The vicinity of this stadium to secondary arterial roads accelerates access to hospitals. According to Figure 6, both stadiums are in good condition in terms of access to emergency stations. The presence of primary and secondary arterial routes facilitates and accelerates emergency access to the stadium.

\section{Proximity to facilities}

One of the fundamental requirements in locating sports centers is to follow the principles of proximity for various facilities. In other words, 
hazardous and problematic facilities should not be located near sports centers and stadiums. As presented in Figure 7, there are several facilities around Takhti Stadium. A greater percentage of these facilities is for residential purposes. The existence of several industrial facilities near the stadium as well as the very susceptible military facility (Barrack of 77th Samen-ol-A'emeh Division) is the most significantly incompatible site near this stadium. The presence of such incompatible facilities is not favorable according to passive defense principles. Due to the stadium being located downtown, open and public green spaces are extremely inaccessible. Apart from
Astan Quds Garden, which is privately owned, there is no decent open and urban green space. Proper facilities adjacent to the stadium include Imam Reza Hospital, which can be utilized at times of crisis. The facilities adjacent to Imam Reza Stadium typically include residential areas, open and green spaces, Astan Quds Razavi Gardens, a several industrial facilities, and other establishments. According to passive defense, as a result of the presence of open and green spaces, parks, hospitals, and medical centers, Imam Reza Stadium is in a much better location than Takhti Stadium since those environments can be put to good use at times of crisis.

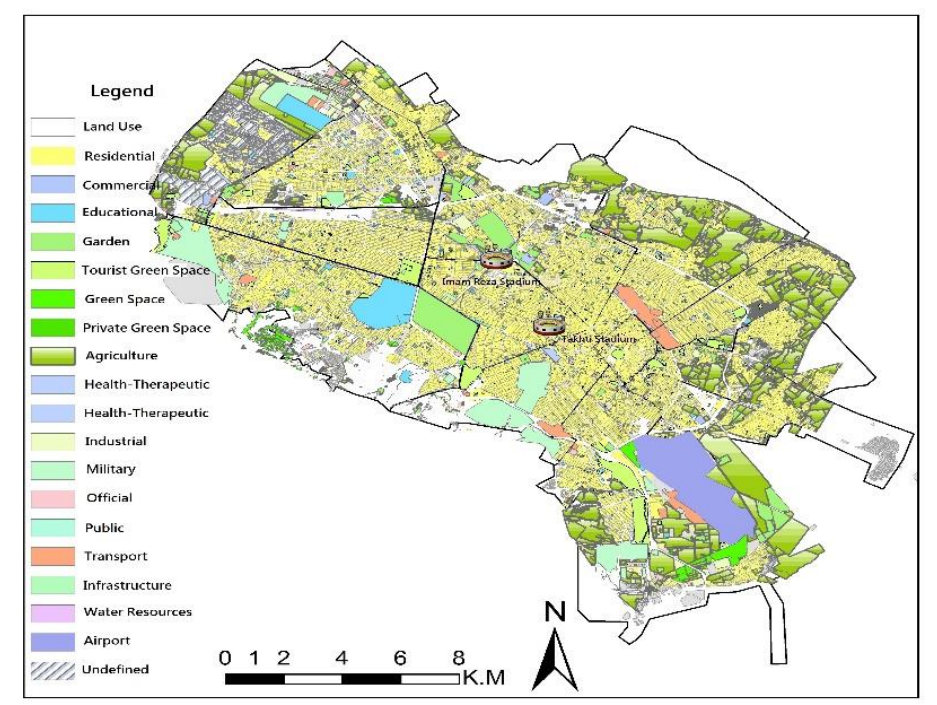

Figure 7. The stadiums' locations with respect to adjacent facilities

\section{Discussion and Conclusion}

Sports uses and particularly football stadiums are some of the most vital uses in cities playing a very significant role in the health and vitality of society. As a result of regular usage and the presence of a large number of citizens and individuals in such places, it is crucial that planners pay special scrutiny to these uses in accordance with passive defense. Complying with passive defense indicators and standards in such facilities can play a positive and central role at times of war and natural disasters. Moreover, it extensively reduces the vulnerability of citizens, facilities, equipment, and infrastructure. In the present study, Takhti and Imam Reza football stadiums in Mashhad were assessed according to the specified indicators in the fields of design and location. Criteria explored in the design and construction of stadiums included compliance with the principles of camouflage and concealment, compliance with the principles of dispersion and decentralization, having a shelter, and the number of entrances and exits for evacuation in case of emergencies. Regarding the principles of camouflage and concealment, it should be noted that these two principles are beneficial strategies to reduce the vulnerability of stadiums and sports venues against attacks. The more concealed these places are from the enemy forces, the more invulnerable they become. The exterior design, planting trees, and employing natural land features can be advantageous in this regard. Following the principles of dispersion and decentralization is another significant criterion of this domain. The more centralization there is in different areas of the stadium, the greater the vulnerability of the central parts is in the 
occurrence of an accident. The research by Hosseini et al. (2014) indicated that the most striking weakness of Razavi Hospital in the design department was the centralization of the majority of hospital sectors in one building (3), which is consistent with the results of the present study. Therefore, decentralization is one of the most influential criteria in passive defense. In addition, possessing a shelter is another key factor protecting people and instilling a sense of security in them in face of potential emergencies. In neither of the sample stadiums, there was no specialized shelter for emergencies. However, hangars and sports halls can function as shelters to some extent. An influential factor in immediate evacuation is an adequate number of entrances and exits. In their research study, Gratz, Church, and Noble (2004) stated that stadium directors should execute measures for the immediate evacuation of stands to protect spectators. Abrupt evacuation of spectators protects their lives and maintains safety against inclement, e.g., snow, rain, and lightning (15). In the sample stadiums, Imam Reza Stadium was in better condition than Takhti Stadium.

The criteria investigated in the domain on location and placement included communication channels and accessibility, safety index, access to hospitals, medical centers, and emergency headquarters, and proximity to facilities. Arterial roads and transportation networks play an extremely crucial role in critical situations. The more accessible primary arteries are to stadiums, the better are their locations. Neither of the target stadiums is directly related to the primary arterial roads. However, Imam Reza Stadium is in better condition since it is directly connected with the secondary arterial road. Access to subway and bus stations can also be of great importance at times of crisis. The study by Hosseini et al. (2014) reported that lack of access to primary arterial roads and the presence of intersections and high traffic in the proximity of Imam Reza Hospital is one of the hospital's weaknesses (3), which is consistent with the results of the present study. One of the stadiums' safety indicators is the quality of access to fire stations. The more adjacent the stadium is to the fire stations, the more and better services it receives in emergencies. Both stadiums are relatively in promising conditions in terms of access to the stations. In case of a potential emergency in stadiums, access to hospitals and medical centers to transport the injured is crucial. Inaccessibility or untimely access to medical centers and hospitals enhances the probability of the injured passing away significantly. It is of great importance to take this point into account while locating sports stadiums. In many sources, especially sports sources, much emphasis has been placed on the presence of appropriate vicinages near stadiums and sports venues. Putting distance between problematic spots and stadiums and surrounding them with appropriate neighbors instead lessens the likelihood of potential disasters. In turn, proper adjacencies can be put into action towards crisis management in the face of emergencies. Open and green spaces, as well as parks, are among appropriate areas to build adjacent to stadiums. On the other hand, factories, military headquarters, and residential areas are among the problematic adjacencies. Imam Reza Stadium is in a favorable condition in terms of proximate places. The study by Hosseini et al. (2014) demonstrated that the proximity of Imam Reza Hospital with military bases has caused the hospital to be in an unfavorable situation according to passive defense (3), which is consistent with the results of the current study. In this study, it was revealed that the vicinity of Takhti Stadium to a military barrack is unsuitable in this domain.

\section{Acknowledgments}

The authors would like to sincerely thank the administrators of Imam Reza and Takhti Sports Complexes, as well as the directors of the Youth and Sports General Directorate of Khorasan Razavi Province for participating in the present study.

\section{Conflict of Interests}

Authors declared no conflict of interests regarding the publication of the present study.

\section{References}

1. Ancey C, Gervasoni C, Meunier M. Computing extreme avalanches. Cold Reg Sci Technol 2004; 39(2-3):161-80.

2. Eckert N, Parent E, Richard D. Revisiting statistical-topographical methods for avalanche predetermination: Bayesian modelling for run out distance predictive distribution. Cold Reg Sci 
Technol 2007;49(1):88-107.

3. Hosseini H, Seddighi A, Hossein Amini $H$. Pathology of Mashhad hospitals with emphasis on passive defense Case study: Razavi and Imam Reza (AS) hospitals. GEOG 2014;12(42):211-238. (In Persian)

4. Karimzadeh M, Ferdows M, Moradi Pardanjani H. Investigating the relationship between passive defense and crisis management. Chaharmahal and Bakhtiari Law Enforcement Quarterly 2016; 4 (13):41-62. (In Persian)

5. Fardro H. Passive defense readiness strategy in passive defense perspectives. Abbasi Publications, Tehran 2008:1-264.

6. Eskandari H. Passive defense knowledge (for managers and experts). Bustan Hamid 2010:14-44. (In Persian)

7. Lane Marcus B. Reviewing the Regional Forest Agreement Experience: The "Wicked Problem" of Common Property forests, Presented at Regional Forest Agreements and the Public Interest: A National Symposium, Australian National University, Canberra, Australia. 2003, 16 July.

8. Hesami L, Jalali Farahani M ,Soleimani KH. Explaining the safety situation of the football stadiums of the professional league of the country. J Sport Manag 2014;6(2):343-59. (In Persian)

9. Akhbari M, Ahmadi Moghadam M. Investigating passive defense in urban management. Political
Geography 2021;10(2):36-69. (In Persian)

10. Mosalanejad A. The Impact of Modernization and Economic Growth on Passive Defense Policy. JISDS 2013;5(3):32-46. (In Persian)

11. Saremi H, Hosseini Amini H. Protection of urban facilities and equipment with optimal use of the natural environment in the city with a passive defense approach (Case study: Borujerd city). Urban Stud 2007;3(6):133-54. (In Persian)

12. Samadi Miarkolaei H, Samadi Miarkolaei $H$. Necessity and importance of the role of hospitals in dealing with natural disasters in crisis management. Second Conference on Environmental Planning and Management, Tehran, University of Tehran 2012:114 (In Persian)

13. Hosseinzadeh D, Maleki K, Shafaati K, Heidarifar A, Raouf M. Fense and sustainable urban development with emphasis on threatened users of Tabriz metropolis from the perspective of war. Geogr Environ Sustain 2012; 5:1-24. (In Persian)

14. Pourmohammadi M, Barandkam F, Maleki K, Shefaati A. Urban planning in proportion to passive defense with emphasis on evaluation and optimal urban land use planning (Case study: Sanandaj city).Sepehr 2012;83:97-107. (In Persian)

15. Gratz J, Church R, Noble E. Lightning safety and outdoor stadiums Sci. Technol. Stud Res Policy 2004;15:1-7. 